\title{
Towards the Capabilities of Rocket Engines with Solar Heating of Working Fluid
}

\author{
V. M. Kotov \\ Republican State Enterprise "National Nuclear Center of the Republic of Kazakhstan", Kurchatov, Republic of Kazakhstan
}

Email address:

kotovvm@nnc.kz

To cite this article:

V. M. Kotov. Towards the Capabilities of Rocket Engines with Solar Heating of Working Fluid. American Journal of Aerospace Engineering. Special Issue: Space Laboratories: History, Researches, Prospects. Vol. 3, No. 1-1, 2015, pp. 1-5. doi: 10.11648/j.ajae.s.2016030101.11

\begin{abstract}
The purpose of this research is to show the potentiality of the rocket with solar heating of working fluid. The study describes design of the heater with tungsten pipes, ensuring full-range application of focusing radiation (95\%) under the hydrogen heating to $2900 \mathrm{~K}$; gives an examples of optimization of rocket engine thrust by the flight time with predetermined fuel weight and specific weight of engine with mirror and payload; illustrates design of the engine and mirrors providing the conjugation between the thrust vector and solar radiation vector; demonstrates design of power-supply source with high-efficient solar energy transformation into electric one and compares various types of the rockets.
\end{abstract}

Keywords: Nuclear Rocket Engine (NRE), Working Fluid, Solar-Heated Rocket Engine, Mass of Engine and Mirrors, Open Space, High-Temperature Reactor Components

\section{Introduction}

The rocketry is a pioneer industry of human activity. In up-to-date perception of its objectives and uses the initial studies are not even hundred years. During this time it became clear enough to understand the potential of rocket technology in the development of the nearest cosmic space. Nevertheless, the big financial assessments and relatively unreliable equipment interfere implementing above tasks although a lot of these are able to be solved both by the international community and separate countries. Search for new technical solutions providing reduced costs and increased reliability is of first-priority in this regard.

The modern rocket engines are the engines using chemical components in their work. This leads to a relatively low specific impulse followed by big gross launching mass, high start-up expenses and low operational reliability. Therefore, the development of the engines with a higher specific fluid impulse is a key direction to improve the technique of space exploration.

Substantial growth of specific impulse is achieved using nuclear rocket engines (NRE), which became possible after becoming the technology of nuclear reactors in the 40-50 years of the 20th century [1,2]. Examples of this type modern device are described in [3] Specific impulse becomes equal to $\sim 900$ s when hydrogen is used as the working fluid of the engine and it is heated to $3000 \mathrm{~K}$.

The same characteristics can be obtained by heating the hydrogen with solar radiation. The advantage of using the solar radiation engines is a lack of problems with storing energy source and transforming one type of the energy into another one. One of example of rocket engine with solar heating of working fluid is described in [4]. There are some problems in the technology of rocket engines with solar heating of working fluid. Let's consider possible solutions to some of them.

\section{Material and Methods / Experimental Details / Methodology}

\subsection{Design of Solar Heater}

Let's use some tungsten pipes irradiated with solar flux from one side in order to heat hydrogen. Let us assume inner pipe diameter of $4 \mathrm{~mm}$, wall thickness of $1 \mathrm{~mm}$ and pipe length of $1 \mathrm{~m}$.

Let's make performance prediction of such a system by hydrogen heating to the temperatures close to $3000 \mathrm{~K}$ according to the program [5]. The hydrogen pressure at the pipe inlet will be assumed as $0.5 \mathrm{MPa}$, and the power applied to each pipe will be $4.28 \mathrm{~kW}$. Fig. 1 shows the temperature distribution of the pipes' and working fluid surfaces along the 
length of the pipes calculated from the condition of uniformity of solar flux along the pipe. It can be seen that the temperature difference between the pipe surface and hydrogen in cross section is reduced when approaching the gas towards the outlet.

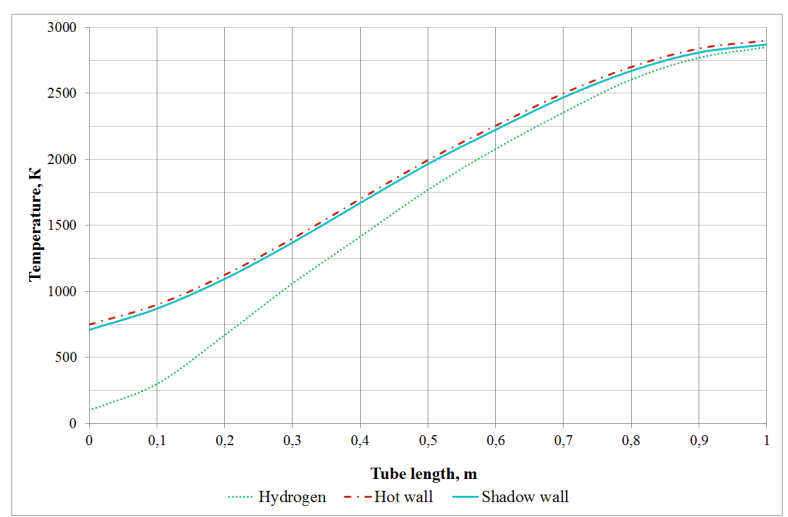

Figure 1. Temperature distribution of the walls and hydrogen along the length of the pipe here.

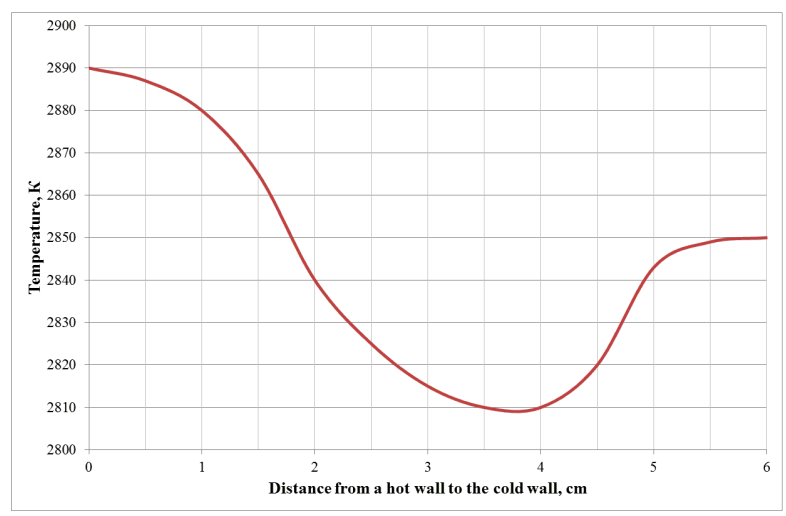

Figure 2. Temperature distribution by diameter of outlet pipe section.

Fig. 2 shows the temperature distribution in the pipe outlet section. It is seen that there is certain contribution into the heat transfer to the hydrogen from the shady pipe side.

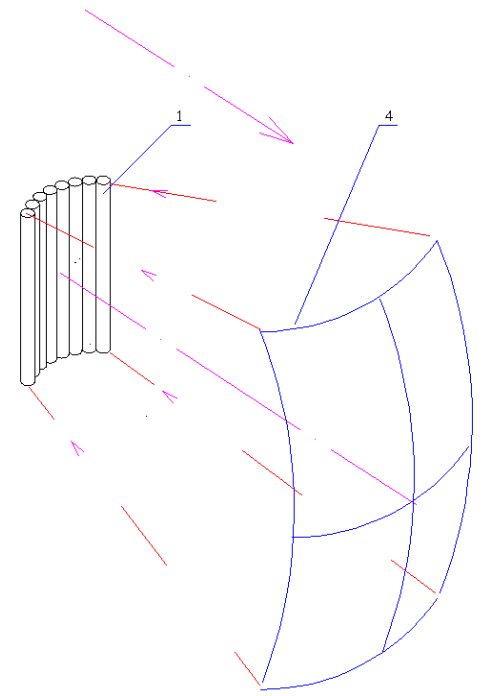

Figure 3. Simplex heater.
Fig. 3 shows a simplex hydrogen heater with tungsten pipes. It is equipped with the set of pipes (1) and focusing mirror (4). The focus of this mirror is behind the place of the pipes. The heater feature is the high losses of thermal energy due to energy radiation in accordance with the Stefan-Boltzmann law.

The heater showed in Fig. 4 provides solar radiation from the mirror 4 into the closed cavity 2 through an orifice of its surface 3 . Heat insulator covers the walls of the cavity 2 . The radiation scattered by pipes is absorbed within the cavity (and on the pipes themselves) reducing the proportion of irretrievably lost energy [6].

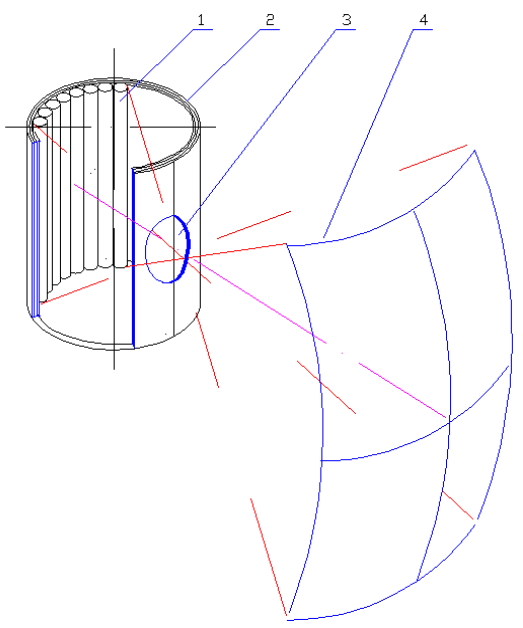

Figure 4. Heater with minimized losses.

Let us estimate energy loss in the heater according to Fig. 3. With given value of solar radiation flux the partial consumption decreased by radiation value according to the Stefan -Boltzmann law having determined by the pipe surface temperature will spend on the hydrogen heating.

Fig. 5 shows the dependences of the fraction of thermal energy transferred from the solar flux to hydrogen in a tubular receiver of this embodiment taken into account temperature increase in pipes' surface under two values of the heat flux density having removed by the hydrogen (200 and $500 \mathrm{~kW} / \mathrm{m}^{2}$ ).

It is seen that the efficiency of energy transfer to the working fluid decreases with increasing temperature and decreasing heat flux density of solar radiation having impacted on the surface of the pipes. The overall efficiency of energy transfer by heating up to $3000 \mathrm{~K}$ and a flow of 500 $\mathrm{kW} / \mathrm{m}^{2}$ is $\sim 18 \%$, and at a flow of $200 \mathrm{~kW} / \mathrm{m}^{2}$ is $\sim 8 \%$.

According to Fig. 4, the losses in the heater will be determined by the probability of scattering the Stefan-Boltzmann radiation from the surface of the pipes in the window 3 of a closed cavity 2 . In the first approximation, this probability can be calculated as the ratio of the surface of the window to the irradiated surface of the pipes. By the Fig. 4 , losses in real heaters will not exceed $5 \%$. 


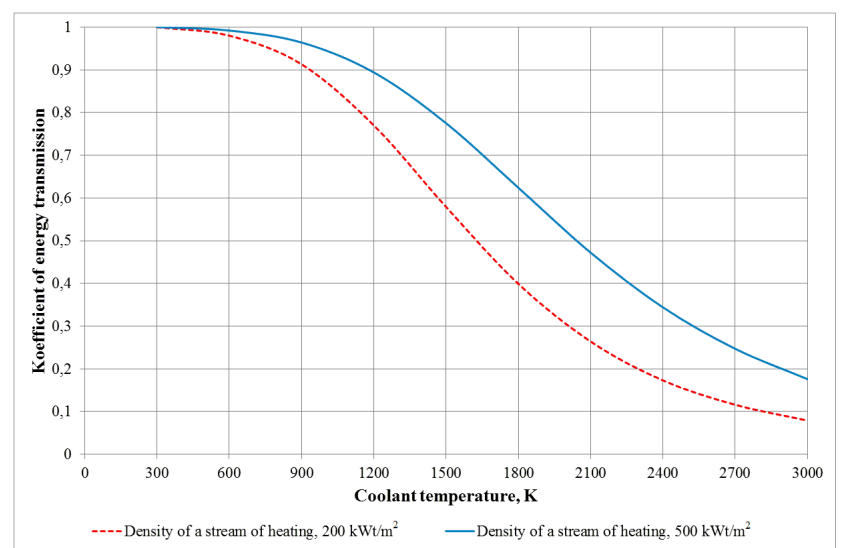

Figure 5. Dependences of the efficient solar energy transfer to the hydrogen in simplex heater under densities of extraction of energy 200 and $500 \mathrm{~kW} / \mathrm{m}^{2}$.

\subsection{Optimization of Solar Heated Rocket Engine Thrust}

By the parameters of tungsten pipe described above it is easy to estimate the minimum specific weight of the engine. If the weight of the pipe is 304 grams, transmitted to hydrogen energy is $4.28 \mathrm{~kW}$, hydrogen heating is $2850 \mathrm{~K}$, hydrogen flow rate is $0.085 \mathrm{~g} / \mathrm{sec}$, so the thrust will be 76 grams and specific impulse of the engine will be $\sim 900 \mathrm{~s}$.

When intensity of solar radiation at the Earth's orbit is 1.37 $\mathrm{kW} / \mathrm{m}^{2}$ and the specific weight of the focusing mirror is $\sim 4$ $\mathrm{kg} / \mathrm{m}^{2}$, so required for mirror mass to heat hydrogen in one pipe will be $12.5 \mathrm{~kg}$. The total mass of the mirrors and the pipe in equivalent of the thrust of $1 \mathrm{~g} / \mathrm{s}$ will be $\sim 150 \mathrm{~kg}$.

In case we take the rocket engines with solar heating thrust equal to the nuclear rocket engine thrust $(6400 \mathrm{~kg})$ for rocket [3], the mass of the solar engine will be close to 1000 tons. This option is completely irrational.

For open space it is rationally to reduce the engine thrust increasing its operation time. The trust value should be optimized according to the flight parameters. In this case, the determinant is not in the maximum achievable speed of the rocket but the flight time from the starting point to the goal.

Dependences of the in-flight time, initial rocket mass and its maximum speed on the engine hydrogen flow were calculated in different options of the initial hydrogen mass in the rocket under specified masses of fuel tanks - hydrogen storages, payload.. Fig. 6 shows the dependences of the initial mass, in-flight time and maximum speed during the flight in the range of hydrogen consumption close to optimal intended for the following initial data:

- Flight distance in the free space (L)

- Initial and final rocket speed

$100 \mathrm{~m} . \mathrm{km}$;

- Hydrogen mass at the beginning

of the flight (Mfuel)

$0 \mathrm{~km} / \mathrm{h}$;

- Mass of hydrogen tanks (Mfuel tanks)

- Mass of the payload (Mpayload)

150 tons;

4.69 tons

6.0 tons.

The optimal hydrogen consumption on the basis of minimum fly time under initial conditions is $\sim 0.05 \mathrm{~kg} / \mathrm{s}$. The more flow rate, the more required heating power and additional weight of the engine and the mirror. An increase in the duration of the acceleration of the rocket becomes important with a decrease in the flow.

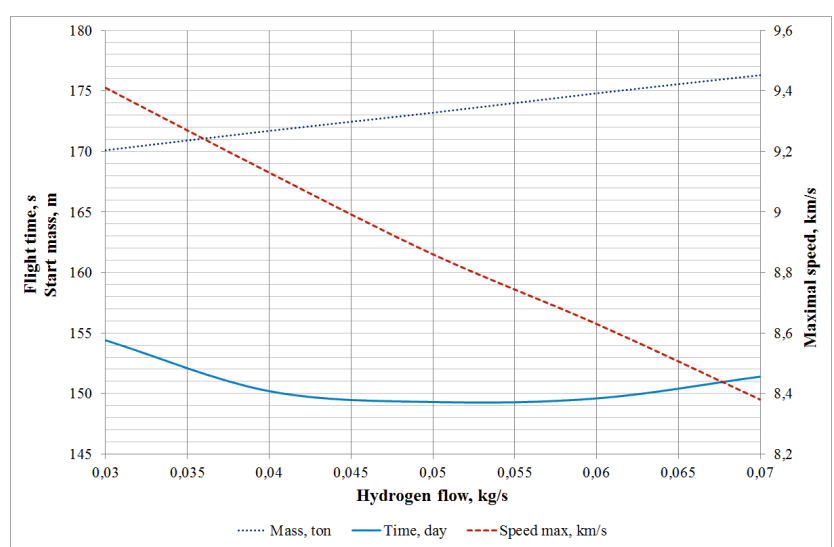

Figure 6. Dependences of in-flight time, initial rocket mass and its maximum speed on hydrogen flow rate. $L=10^{8} \mathrm{~km}$, Mfuel $=150 \mathrm{t}$, Mfuel tanks $=4.69$ $m$, Mpayload $=6.0 t, V 0=V k=0$.

\subsection{Comparison of the Rocket with Solar Heating of Working Fluid (SRE) and Nuclear-Heated Propellant (NRE)}

Fig. 7 provided minimum in-flight times of SRE and NRE, and its mass, under the same initial conditions but with different initial hydrogen masses [3].

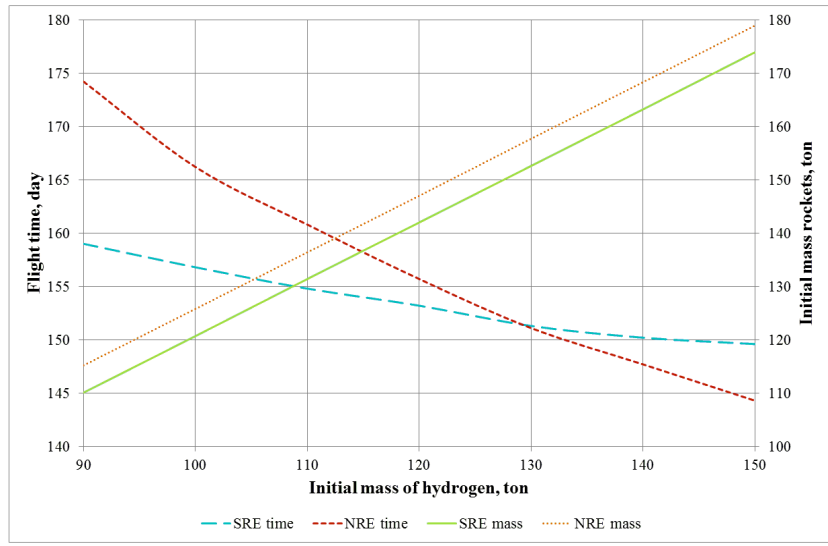

Figure 7. Dependences of in-flight time and rocket mass with SRE and NRE on hydrogen mass. $L=10^{8} \mathrm{~km}$, Mfuel tank $=4.69 \mathrm{t}$, Mpayload $=6.0 \mathrm{t}$, V0= $V k=0$

It appears, that solar rocket engine benefits the in-flight time when hydrogen mass is less than 130 tons. In-flight time change in given range of hydrogen mass is 3.2 times less for SRE than for NRE.

It should be noted that increase in hydrogen mass is lead to both growing the total initial rocket mass, its value grain and loss in operation reliability. It follows, that the version of SRE rocket and initial hydrogen mass of 90 tons looks more preferable rather than NRE rocket with initial hydrogen mass of 150 tons.

\subsection{Item Design of the Rocket with Solar Heating of Working Fluid}

In comparison with other rockets, the rocket with solar 
heating of working fluid has one feature as presence of a radiating scarce (the Sun) used as an orienting point for focusing mirror if it is necessary to orient the engine power in any direction toward the source. The task is to provide the rocket nozzle having oriented in other direction with solar radiation energy produced from one direction in one form or another.

This problem can be solved by various ways. For this, paper [4] uses transformation of solar radiation into electrical current, heat of high-temperature heat-exchanging unit accumulator with the current. It isn't complicated to transfer the power from solar panel to the heat-exchanging unit rigidly bound with rocket effluent nozzle. However, this design has low conversion efficiency of solar radiation into electric power.

Fig. 8 shows a scheme in which the conjugation of the vectors is achieved by means of movable connections of the hydrogen supplying line to the heater and supply line from the heater to the nozzle. Since, there are two mating vectors, there is always will be a plane in which they are both located. The use of one group of such connections lead to the plane of the vectors will pass through the body of the missile. The decision of the problem is to separate focusing mirror and the engine for two symmetric objects [7].By the parameters of tungsten pipe described above it is easy to estimate the minimum specific weight of the engine. If the weight of the pipe is 304 grams, transmitted to hydrogen energy is $4.28 \mathrm{~kW}$, hydrogen heating is $2850 \mathrm{~K}$, hydrogen flow rate is $0.085 \mathrm{~g} / \mathrm{sec}$, so the thrust will be 76 grams and specific impulse of the engine will be $\sim 900 \mathrm{~s}$.
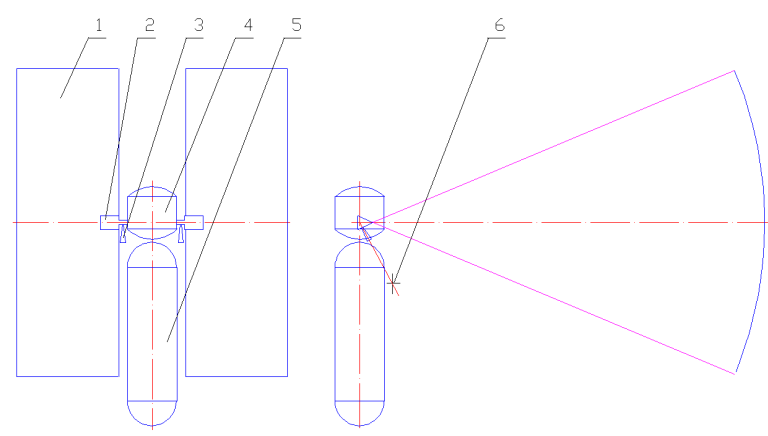

Figure 8. Solar -heated rocket. 1 -Focusing mirror, 2 -heaters, 3 - engine nozzles, 4-payload module, 5 - fuel tank, 6 -rocket centre of gravity.

Heaters 2 in this scheme are made by drawing 4 . Connection of hydrogen supply line from the missile body to the highway entrance to the solar heater and line of hydrogen release from the heater to the highway entrance to the rocket nozzle is shown in Fig. 9.

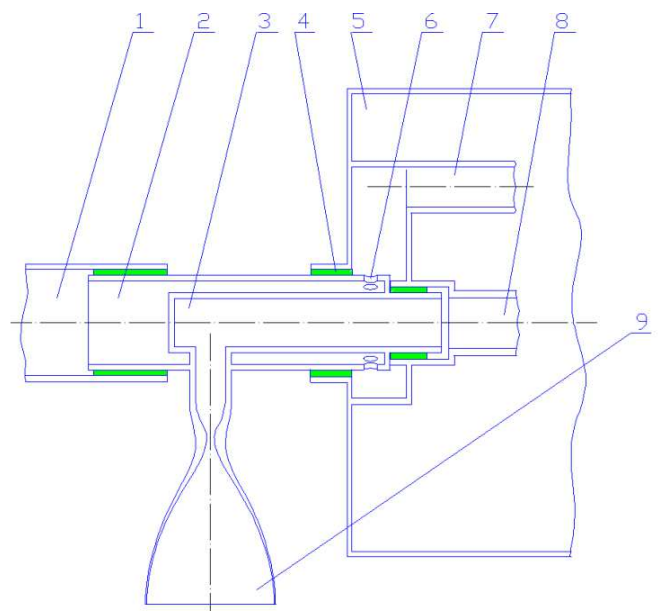

Figure 9. Diagram of junction the rocket vessel elements with the heater and nozzle. 1 - stationary propellant feed pipe, 2 - moving feed pipe, 3 - pipe feeding the propellant to the nozzle, 4 - seal, 5 - heater body, 6-holes, 7 pipe feeding the propellant to the heater, 8 - hot propellant pipe, 9 -nozzle.

\subsection{Moon Mission Parameters}

Let's consider options for flight to the Moon, which are different by composition of the payload and the conditions approaching to the Earth on the return flight:

1. Flight of the crew from the Earth's orbit to the Moon's orbit and return to the Earth at a speed of $11 \mathrm{~km} / \mathrm{s}$.

2. Flight of the crew from the Earth's orbit to the Moon's orbit and return to the Earth's orbit.

3. Shipping to the Moon's orbit landing module (lunar module) and return the rocket to the Earth's orbit.

4. Flight to the Moon's orbit landing module and a crew and the crew's return to the Earth's orbit.

Table 1. Main characteristics of flight options to the Moon

\begin{tabular}{|c|c|c|c|c|}
\hline Parameter & Option 1 & Option 2 & Option 3 & Option 4 \\
\hline $\begin{array}{l}\text { Start mass on the Earth, } \\
\text { ton }\end{array}$ & 310 & 400 & 1100 & 1400 \\
\hline $\begin{array}{l}\text { Mass on the Earth's } \\
\text { orbit, kg }\end{array}$ & 7965 & 10342 & 28050 & 35700 \\
\hline Lunar module mass, $\mathrm{kg}$ & 0 & 0 & 14000 & 14000 \\
\hline $\begin{array}{l}\text { Fuel mass on the } \\
\text { Earth's orbit, } \mathrm{kg}\end{array}$ & 3165 & 5542 & 10650 & 14700 \\
\hline $\begin{array}{l}\text { Mirrors, heater and } \\
\text { engine mass, } \mathrm{kg}\end{array}$ & 1200 & 1200 & 3400 & 3400 \\
\hline Dwelling unit mass, $\mathrm{kg}$ & 3600 & & 0 & 3600 \\
\hline Mirrors area, $\mathrm{m}^{2}$ & 229,4 & 229,4 & 659,5 & 659,5 \\
\hline Engine thrust, $\mathrm{N}$ & 80 & 80 & 230 & 230 \\
\hline $\mathrm{T} 1$, hours & 81,25 & 103 & 98 & 124,5 \\
\hline $\mathrm{T} 2$, hours & 17,8 & 18 & 6 & 9,3 \\
\hline $\mathrm{T} 3$, hours & 0 & 55 & 13 & 25 \\
\hline
\end{tabular}

Here: T1 - engines working time in flight to the Moon, T2 engines working time in flight from the Moon's orbit, T3 engines working time while deceleration during the return to Earth's orbit.

May be options 2 and 3 will be more preferred, they are carried out separately delivery of the crew and lunar modules with reusable solar rocket engines in flight to the Moon and return to the Earth's orbit.

The main thing is that it reduces the cost of the Project on 
flights to the Moon and makes possible to improve performance of the lunar rocket by decreasing its mass and increasing security at the expense of low- encroaching speed to the Earth with earth satellite arrival in the orbit.

\subsection{Power-Supply Source}

Long-running solar rocket engines during the flight to the Mars make it possible to develop generators with a very high efficiency of conversion of thermal energy into mechanical one [8]. Figure 10 provides a diagram of the generator. According to this diagram a refrigerator of a heat machine is used to heat a cryogenic working body so the thermal energy of all the processes fully utilizes.

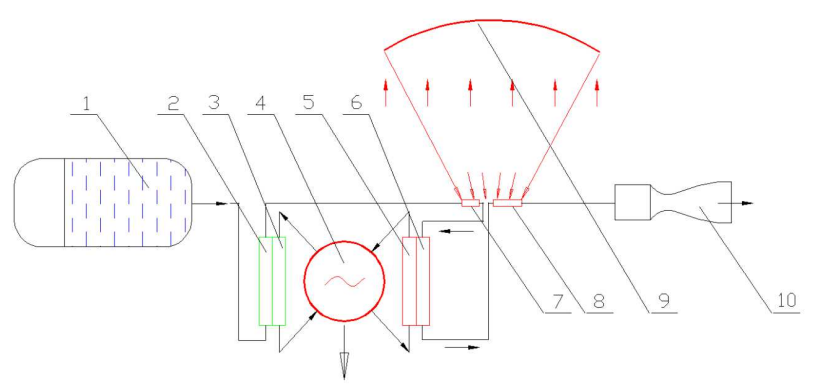

Figure 10. Rocket with solar heating of working fluid power-supply source. 1 -vessel with a working fluid, 2 -working fluid heater, 3 - heat machine refrigerator, 4 - heat machine, 5, 6-heat exchanger of heat machine, 7 solar heater of a heat machine, 8 - engine heater, 9 - focusing mirror, 10 engine nozzle. -heated rocket

The rocket with mirror area of $229 \mathrm{~m} 2$ when coefficient of efficiency of $20 \%$ and minimum cycle temperature of $300 \mathrm{~K}$ is able to achieve electric power of $7.8 \mathrm{~kW}$ at engine burn.

The $2.5 \%$ of the solar flux (approximately $6 \mathrm{~m}^{2}$ of the mirror) is tapped herewith off. Using solar panels with the same electrical power would require additional panel with an area of $\sim 40 \mathrm{~m}^{2}$.

\section{Conclusion}

Heater with tungsten pipes ensures hydrogen heat up to $2900 \mathrm{~K}$ with high density of focused solar energy flux and hydrogen pressure at inlet $0.5 \mathrm{MPa}$.
Heater with closed cavity design, which ensures high effectiveness of solar energy transfer to hydrogene (>95\%), is presented.

Necessity of the trust value optimization according to the flight parameters with determined fuel mass, specific weight of the engine with the focusing mirror, and mass of payload, is shown.

The engine with the focusing mirror design, which ensures solar flux and rocket propulsion vectors conjugation, is presented.

The power-supply source design with high-efficient solar energy transformation into electric one is demonstrated.

Comparison of various types of the rockets is shown.

\section{References}

[1] Bussard R., De Lauer R. Los Alamos Scientifie University of California. McGrow-Hill Book Company, Inc. New York-Toronto-London; 1958.

[2] Bussard R., De Lauer R. Fundamentals of Nuclear Flight. New York; 1966.

[3] Romadova E.L., Smetannikov V.P., Cherepnin Yu.S. etc. Nuclear power and power propulsion systems for space exploration. Nuclear Energy in the Republic of Kazakhstan. International Scientific and Technical Conference. Kurchatov; 2005.

[4] Koroteev A.S., Akimov V.N., Arkhangelsky V.I., Kuzmin E.P. Solar thermal rocket engine. Patent of Russia No. 2126493 of Feb. 20; 1999.

[5] Fluent version 6.3.26 User Reference. Fluent, Inc.; 2006.

[6] Kotov V.M. High-temperature solar heater. Innovative patent of the Republic of Kazakhstan. No. 22587 of Jun 15, 2010.

[7] Kotov V.M. Rocket with a solar fluid heating. Innovative patent of the Republic of Kazakhstan. No. 22933 of Sept 15, 2010.

[8] Kotov V.M. Energy source for a solar-heated rocket engine. Innovative patent of the Republic of Kazakhstan. No.22809 of Aug 15, 2010. 